\title{
Effect of forest bathing trips on human immune function
}

\author{
Qing Li
}

Received: 14 July 2008/Accepted: 6 December 2008/Published online: 25 March 2009

(C) The Japanese Society for Hygiene 2009

\begin{abstract}
In Japan, a forest bathing trip, called "Shinrinyoku" in Japanese, is a short, leisurely visit to a forest; it is regarded as being similar to natural aromatherapy. This review focuses on the effects of forest bathing trips on human immune function. Beginning in 2005, adult Japanese individuals, both male and female, participated in a series of studies aimed at investigating the effect of forest bathing trips on human immune function. The subjects experienced a 3-day/2-night trip to forest areas, and blood and urine were sampled on days 2 (the first sampling during each trip) and 3 (the second sampling during each trip), and on days 7 and 30 after the trips. Natural killer (NK) activity, the numbers of NK, granulysin-, perforin-, and granzymes A/B-expressing lymphocytes in the blood, and the concentration of urinary adrenaline were measured. The same measurements were made before the trips on a normal working day as a control. The mean values of NK activity and the numbers of NK, granulysin-, perforin-, and granzymes $\mathrm{A} / \mathrm{B}$-expressing cells on forest bathing days were significantly higher than those on the control days, whereas the mean values of the concentration of urinary adrenaline on forest bathing days were significantly lower than that on the control days in both male and female subjects. The increased NK activity lasted for more than 30 days after the trip, suggesting that a forest bathing trip once a month would enable individuals to maintain a higher level of NK activity. In contrast, a visit to the city as a tourist did not increase NK activity, the numbers of NK
\end{abstract}

Q. Li (ه)

Department of Hygiene and Public Health,

Nippon Medical School, 1-1-5 Sendagi,

Bunkyo-ku, Tokyo 113-8602, Japan

e-mail: qing-li@nms.ac.jp

URL: http://forest-medicine.com cells, or the level of intracellular granulysin, perforin, and granzymes A/B. These findings indicate that forest bathing trips resulted in an increase in NK activity, which was mediated by increases in the number of NK cells and the levels of intracellular granulysin, perforin, and granzymes $\mathrm{A} / \mathrm{B}$.

Keywords Forest bathing - Granulysin .

Granzyme $\cdot$ NK activity $\cdot$ Perforin

\section{Introduction}

What is a forest bathing trip?

The forest environment has been enjoyed by humans for a long time because of the quiet atmosphere, beautiful scenery, mild climate, and clean fresh air in forests. In Japan, a forest bathing trip, called "Shinrinyoku" in Japanese, is a short, leisurely visit to a forest and is regarded as being similar to natural aromatherapy. A forest bathing trip involves visiting a forest for relaxation and recreation while breathing in volatile substances, called phytoncides (wood essential oils), which are antimicrobial volatile organic compounds derived from trees, such as $\alpha$-pinene and limonene [1-4]. Incorporating forest bathing trips into a good lifestyle was first proposed in 1982 by the Forest Agency of Japan. It has now become a recognized relaxation and/or stress management activity in Japan [2-6]. The results of a study using the Profile of Mood States (POMS) test demonstrated that a forest bathing trip significantly increased the score for vigor and decreased the scores for anxiety, depression, and anger [2, 4]. Habitual forest bathing may help to decrease the risk of psychosocial stress-related diseases [6]. Because forests 
occupy $67 \%$ of the land in Japan [7], forest bathing is easily accessible, and according to a public opinion poll conducted in Japan in 2003, 25.6\% of respondents had participated in a forest bathing trip, indicating its popularity in Japan [6]. Moreover, forest bathing is possible in similar environments throughout the world.

\section{Effect of phytoncides (essential oils) from trees on human immune function}

To investigate the effect of a forest bathing trip on human immune function, the effects of phytoncides on human natural killer (NK) activity and intracellular levels of perforin, granzyme A (GrA), and granulysin (GRN) in $\mathrm{NK}$ cells were studied in vitro. NK cells have been reported to kill tumors or virus-infected cells through the release of perforin, granzymes, and GRN via the granule exocytosis pathway [8-12]. Li et al. [1] incubated NK-92MI cells, an interleukin-2-independent human NK cell line, in the presence of phytoncides, such as $\alpha$-pinene, 1,8-cineole, $d$-limonene, and essential oils extracted from trees including Japanese cedar (Cryptomeria, Sugi in Japanese) and Chamaecyparis obtuse (Hinoki in Japanese), for 48$144 \mathrm{~h}$ and then measured NK activity and the intracellular levels of perforin, GrA, and GRN [1]. They found that phytoncides significantly increased the cytolytic activity of NK-92MI cells in a dose-dependent manner and significantly increased the intracellular levels of perforin, GrA, and GRN in NK-92MI cells. Phytoncides also partially, but significantly, restored the decreased human NK activity and the decreased perforin, GrA, and GRN levels in NK-92MI cells induced by dichlovos, an organophosphorus pesticide. Pretreatment with phytoncides partially prevented dichlovos-induced inhibition of NK activity. Taken together, these data indicate that phytoncides significantly enhance human NK activity and that this effect is at least partially mediated by the induction of intracellular perforin, GrA, and GRN [1]. Komori et al. [13] reported that the citrus fragrance found in forests affected human endocrine and immune systems, based on the measurement of urinary cortisol and dopamine levels, NK activity, and CD4/8 ratios. da Silva et al. [14] found that volatile oil from Zanthoxylum rhoifolium Lam leaves and certain terpenes ( $\alpha$-humulene, $\beta$-caryophyllene, $\alpha$-pinene, and $\beta$-pinene) exhibited anti-tumor efficacy and significant immunomodulatory action in vivo and in vitro in mice. Moreover, Grassmann et al. [15] found that the essential oil from Pinus mugo showed antioxidative properties. All of these findings strongly suggest that forest environments (forest bathing trip) have beneficial effects on human immune function. However, to date, there have been no published reports on the effect of forest bathing on human immune function, with the exception of the studies conducted by this author.

\section{Effect of forest bathing trips on human immune function}

Within the framework of published results on forest bathing trips, since 2005, a series of investigations with both Japanese female and male subjects have been carried out with the aim of studying the effect of forest bathing on human immune function. To this end, investigators measured human NK activity and the numbers/proportions of NK and T cells, perforin-, GrA/B-, and GRN-expressing lymphocytes in human peripheral blood lymphocytes (PBLs) in the subjects during visits to forest areas in Japan [2-4].

In the first study [2], 12 healthy male subjects, aged 3755 years $(43.1 \pm 6.1$ years), were selected from three large companies in Tokyo, Japan. The sociodemographic information on the subjects, including age and lifestyle habits, was obtained by means of a self-administered questionnaire and has been reported previously [16]. None of the subjects had any signs or symptoms of infectious diseases, used drugs that might affect immunological analysis, or were taking any medication at the time of the study. It was also confirmed that none of the subjects had taken forest bathing trips within at least 3 months prior to the study. In early September 2005, the subjects participated in a 3-day/ 2-night trip to forest areas at Iiyama, Nagano prefecture, located in northwest Japan. On day 1, the subjects walked about $2.5 \mathrm{~km}$ in a forest field in about $2 \mathrm{~h}$, which approximates the amount of normal physical activity the subjects would have on an average working day. The participants were allowed to rest anywhere and anytime they liked. On day 2, they walked about $2.5 \mathrm{~km}$ in the morning and afternoon (each time approx. $2 \mathrm{~h}$ ), respectively, in two different forest fields. On day 3 , the subjects finished the trip, and after providing blood samples and completing a questionnaire survey, they returned to Tokyo. The main trees in the forests were Japanese cedar (Cryptomeria), Japanese beech, and Japanese oak. Blood samples were taken on the second (the first sampling during the trip) and third days (the second sampling during the trip). White blood cell (WBC) counts, NK activity, numbers of NK and $\mathrm{T}$ cells, and numbers of GRN-, perforin-, and GrA/ B-expressing lymphocytes were determined in the blood samples. The same measurements were made before the trips on a normal working day as a control. Blood was sampled at 0800 hours on all occasions. To control for the effect of alcohol on NK activity, the subjects did not consume alcohol for 2 days before providing the blood samples. The subjects did not take hot spring baths or eat 
any special foods, such as herbs and alcoholic drinks, which may have affected the immune function during the trip. Phytoncide concentrations in forest air samples were also measured.

There were significant differences in NK activity (Fig. 1a) and in the numbers of NK cells (Fig. 1b) both before and after the trip and between days 1 and 2, indicating that the forest bathing trip significantly increased NK activity (Fig. 1a) and the numbers of NK cells (Fig. 1b). It has been reported that NK cells kill tumor or virus-infected cells through the release of perforin, granzymes, and GRN via the granule exocytosis pathway [8-12]. In order to explore the mechanism of enhancement of NK activity induced by forest bathing, the effect of forest bathing on the intracellular levels of perforin, GRN, and GrA/B in PBL was investigated. The results showed that the forest bathing trip also significantly increased the numbers of intracellular perforin-, GRN-, and GrA/B-expressing lymphocytes (Fig. 2). Taken together, these findings indicate that a forest bathing trip can increase NK activity and that this effect might be at least partially mediated by increasing the number of NK cells and by the induction of intracellular perforin, GRN, and GrA/B [2].

\section{How long does the increased NK activity last after a forest bathing trip?}

Following the first study, two questions remained to be resolved: (1) will a trip to places without forest (a city tourist visit) also increase NK activity? (2) How long does the increased NK activity last after a forest bathing trip or a city tourist visit? Two investigations were then conducted to address these two questions [3]. Twelve healthy male subjects, aged 35-56 years (mean $45.1 \pm 6.7$ years), were selected from four large companies in Tokyo, Japan. Information on the subjects was gathered from a selfadministered questionnaire, including age and lifestyle habits, as described previously [16]. None of the subjects had any signs or symptoms of infectious disease, used drugs that may affect the immunological analysis, or were taking any medication at the time of the study. It was also confirmed that none of the subjects had taken forest bathing trips within at least 3 months prior to the study. In early September 2006, the subjects experienced a 3-day/2-night trip to three different Chamaecyparis obtuse (Japanese cypress, Hinoki in Japanese) forests around Agematsu town, Nagano prefecture, located in northwest Japan. The schedule of the forest bathing trip was similar to that described previously [2]. Prior to the forest visit, in midMay 2006, 11 of the same 12 subjects participated in a city tourist visit consisting of 3-day/2-night trip to Nagoya city
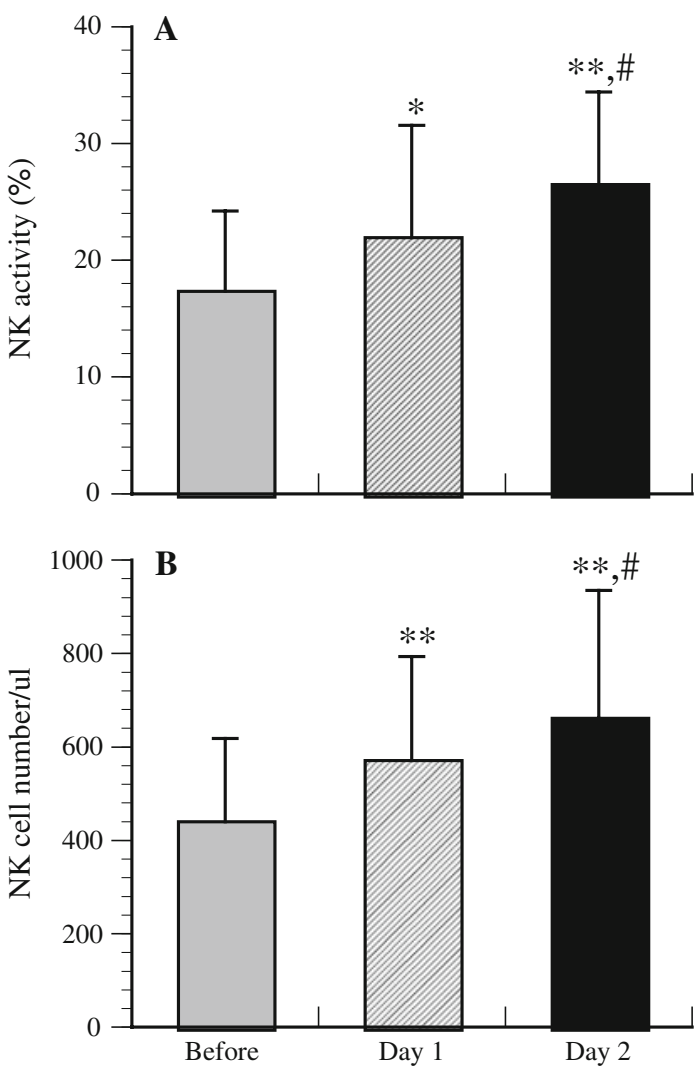

Fig. 1 Effect of a forest bathing trip on natural killer $(N K)$ activity (a) and the number of NK cells (b). Columns: Before values obtained before the trip, Day 1 values obtained after the first day of the trip, Day 2 values obtained after the second day of the trip. Data are presented as the mean \pm standard deviation (SD) $(n=12)$. $* P<0.05, * * P<0.01$, significantly different from before the trip, ${ }^{\#} P<0.05$ significantly different from day 1 by paired $t$ test. Cited from $\mathrm{Li}$ et al. [2]

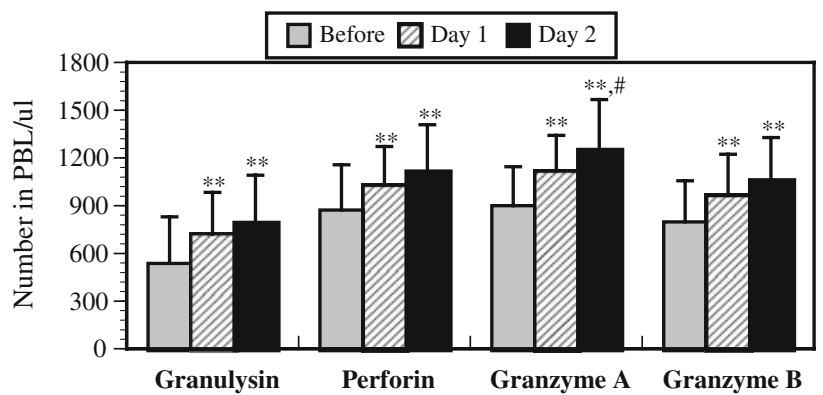

Fig. 2 Effect of a forest bathing trip on the number of granulysin-, perforin-, and granzymes A/B-expressing cells in peripheral blood lymphocytes $(P B L s)$. Data are presented as the mean $\pm \mathrm{SD}(n=12)$. $* P<0.05, * * P<0.01$, significantly different from before the trip, ${ }^{\#} P<0.05$ significantly different from day 1 by the paired $t$ test. Cited from $\mathrm{Li}$ et al. [2]

$[2,3]$. On the first day, the subjects walked for $2 \mathrm{~h}$ in the afternoon along a tourist route through a historical district of Nagoya city and then stayed at a hotel in Nagoya. On the second day, the subjects walked for $2 \mathrm{~h}$ around Nagoya 
baseball Dome in the morning and 2 hours around/in Nagoya airport nearby Nagoya city in the afternoon. There are some tree-covered areas in Nagoya city, but there are almost no trees in the areas visited. The class of hotel and the lifestyle of the subjects during the stays in the hotels were the same for the city and forest trips. The walking courses in both trips were $2.5 \mathrm{~km}$, as in the previous study [2]. Blood was sampled at 0800 hours on the second (the first sampling during each trip) and third days (the second sampling during each trip), on days 7 and 30 after the forest bathing trip, and 3 days prior to the trips (control). The WBC counts, NK activity, proportions of NK and T cells, and GRN-, perforin-, and GrA/B-expressing cells in PBLs were measured. The concentration of adrenaline in urine was also determined. To control for the effect of alcohol on NK activity, the subjects did not consume alcohol for 2 days prior to blood sampling, including before and during the trips, and after the trip on days 7 and 30. The purpose of setting the control experiment in a city in this study was to determine whether just taking a trip (city tourist visit) can also affect NK activity.

There were significant differences in NK activity (Fig. 3a), the numbers of NK cells (data not shown), and the percentages of GRN-, perforin-, and GrA/B-expressing cells in PBLs (Fig. 4a) between before and after the forest bathing trip, suggesting that this trip significantly increased human NK activity, the number of $\mathrm{CD} 16^{+} \mathrm{NK}$ cells, and the percentages of GRN-, perforin-, and GrA/B-expressing cells in PBLs. These results confirmed the earlier findings [2]. The increases in NK activity and number of $\mathrm{CD} 16^{+}$ NK cells and the higher percentages of GRN-, perforin-, and $\mathrm{GrA} / \mathrm{B}$-expressing cells lasted for more than 7 days, while the increased NK activity and the higher number of NK cells and GRN- and GrB-expressing cells lasted for 30 days (Figs. 3a, 4a). In contrast, the city tourist visit did not increase human NK activity, numbers of NK cells, or the expression of the selected intracellular perforin, GRN, and GrA/B (Figs. 3b, 4b). Phytoncides, such as alpha-pinene and beta-pinene, were detected in the forest air, but were almost absent from city air. These findings indicate that a forest bathing trip increased NK activity, the number of NK cells, and the levels of intracellular perforin, GRN, and $\mathrm{GrA} / \mathrm{B}$, and that these effects lasted for at least 7 days after the trip [3]. The most important finding of these studies is that visiting a forest—but not a city—increases NK activity and the intracellular levels of perforin, GRN, and GrA/B. Phytoncides released from the trees may partially contribute to increased NK activity [1].

\section{Effect of forest bathing trips on NK activity in female subjects [4]}

Although these studies demonstrated that forest bathing trips were able to enhance human NK activity in male subjects, the question remaining to be resolved was whether or not forest bathing trips would also increase NK activity in female subjects. It has been reported that menstrual cycle significantly affects NK activity [17]; consequently, the influence of the menstrual cycle on NK activity should be controlled for in experiments with female subjects.

In this study [4], 13 healthy nurses, aged $25-43$ years (mean $28.8 \pm 4.6$ years) and active in their profession for 4-18 years (mean $6.7 \pm 3.8$ ), were selected with informed consent. None of the subjects had any signs or symptoms of infectious disease, used drugs that may affect immunological analysis, or were taking any medication at the time of the study. The subjects experienced a 3-day/2-night trip to forest fields around Shinano town, Nagano prefecture, located in northwest Japan in early September 2007. The schedule of the forest bathing trip and blood sampling was similar to that described for the earlier studies [2, 3], and the same blood/urine tests were carried out (WBC counts, $\mathrm{NK}$ activity, numbers of $\mathrm{NK}$ and $\mathrm{T}$ cells, and GRN-, perforin-, and GrA/B-expressing lymphocytes in the blood samples; concentrations of adrenaline and noradrenaline in urine) as well as tests measuring the concentrations of
Fig. 3 Effect of a forest bathing trip (a, $n=12)$ and a city tourist visit $(\mathbf{b}, n=11)$ on $\mathrm{NK}$ activity. Data are presented as the mean \pm SE. $* P<0.05$, $* * P<0.01$, significantly different from before the trip by paired $t$ test. Cited from Li et al. [3]
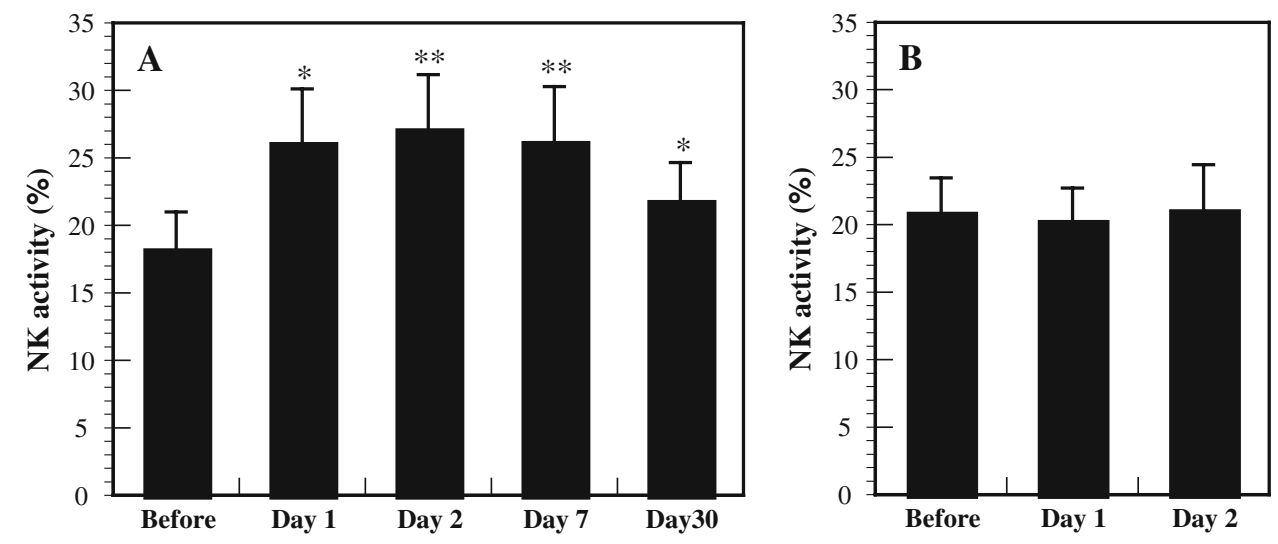

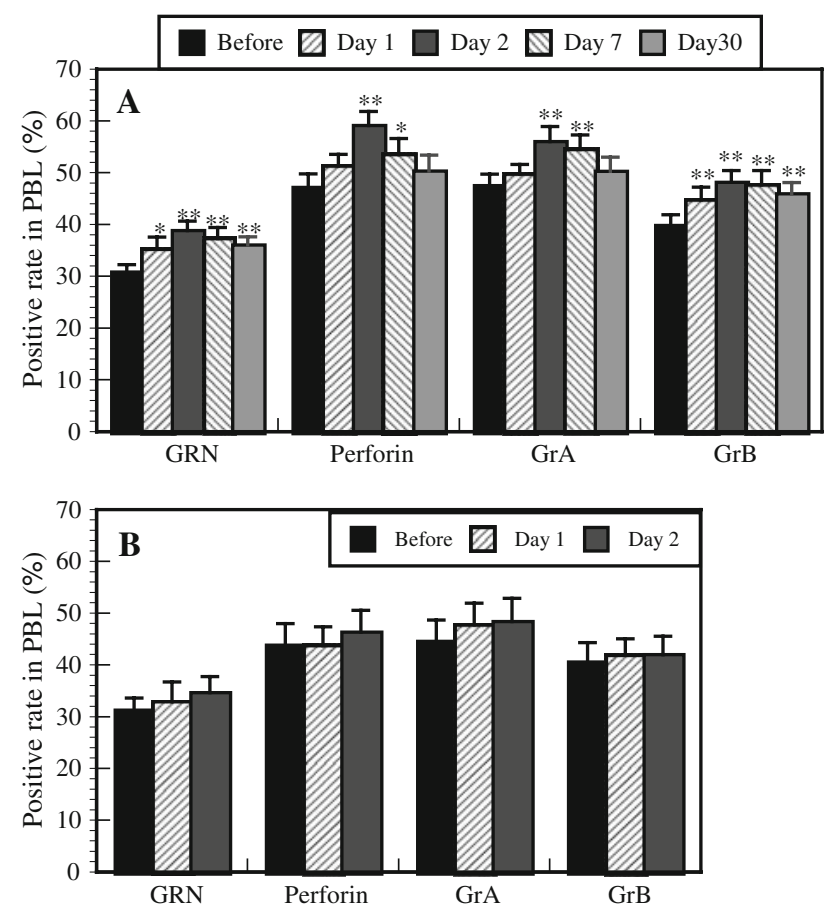

Fig. 4 Effect of a forest bathing trip $(\mathbf{a}, n=12)$ and a city tourist visit $(\mathbf{b}, n=11)$ on granulysin- $(G R N)$, perforin-, and granzymes $(G r)$ $\mathrm{A} / \mathrm{B}$-expressing cells in PBLs. Data are presented as the mean $\pm \mathrm{SE}$. ${ }^{*} P<0.05,{ }^{*} P<0.01$, significantly different from before the trip by paired $t$ test. Cited from Li et al. [3]

estradiol and progesterone in serum. The same control measurements were made before the trip on a normal working day. Blood was sampled at 0800 hours on all days. The concentrations of phytoncides in the forests were measured.

The forest bathing trip significantly increased NK activity (Fig. 5) and the positive rates of NK (Fig. 6) and perforin-, GRN-, and GrA/B-expressing cells (Fig. 7). The increased NK activity (Fig. 5) and the positive rates of NK (Fig. 6) and perforin-, GRN-, and GrA/B-expressing cells (Fig. 7) lasted for more than 7 days after the trip [4], which confirmed the previous findings in male subjects [3]. Phytoncides, such as alpha-pinene and beta-pinene, were detected in forest air. These findings indicate that a forest bathing trip also increased NK activity, number of NK cells, and the levels of intracellular anti-cancer proteins in female subjects and that this effect lasted for at least 7 days after the trip. Phytoncides released from trees may partially contribute to the increased NK activity [1, 4]. A forest bathing trip was found to significantly decrease the percentage of $\mathrm{T}$ cells in female subjects (Fig. 8) [4]. It has been reported that mental stress increases $\mathrm{T}$ cell levels among PBLs $[17,18]$ and that people with a poor lifestyle have a higher percentage of $\mathrm{T}$ cells than people with a good lifestyle [16]; therefore, it can be speculated that the proportion of $\mathrm{T}$ cells in PBLs may reflect stress status.

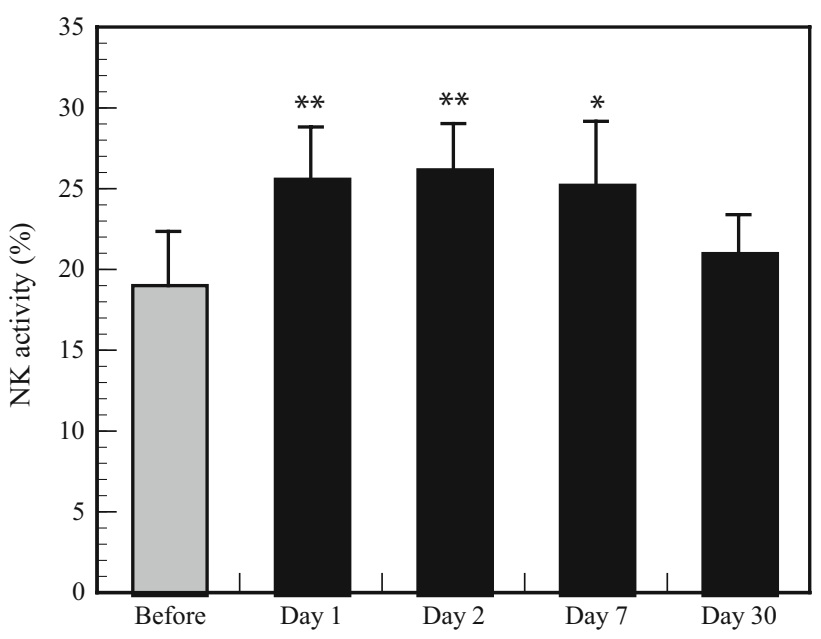

Fig. 5 Effect of a forest bathing trip on NK activity in female subjects. Data are presented as the mean $\pm \mathrm{SE}(n=13)$. $* P<0.05$, $* * P<0.01$, significantly different from before the trip by the paired $t$ test. Cited from Li et al. [4]

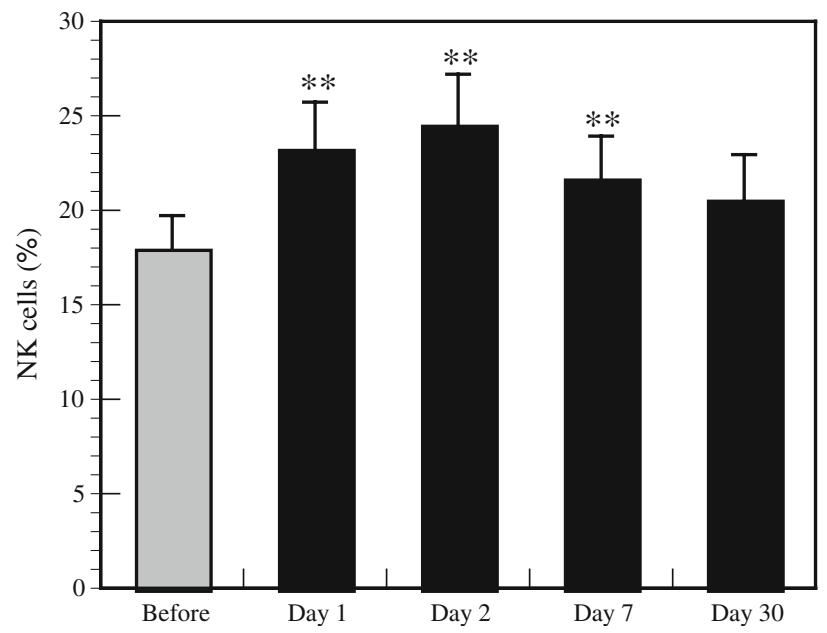

Fig. 6 Effect of a forest bathing trip on the percentage of NK cells. Data are presented as the mean $\pm \operatorname{SE}(n=13)$. $* * P<0.01$, significantly different from before the trip by the paired $t$ test. Cited from Li et al. [4]

Souza et al. reported that NK activity is significantly higher in the follicular phase of the menstrual cycle than in the luteal phase and that the levels of NK activity in postmenopausal women are similar to those of women in the follicular phase but significantly higher than those of women in the luteal phase [19]. Conversely, Yovel et al. [20] reported that the menstrual cycle had no significant effect on the activity levels of NK cells. Roszkowski et al. [21] found that patients with low $(<50 \mathrm{pg} / \mathrm{ml})$ and high $(>200 \mathrm{pg} / \mathrm{ml})$ estradiol levels showed an increase and a decrease of NK cell activity, respectively. Progesterone at 100-400 nM $(31.45-125.8 \mathrm{ng} / \mathrm{ml})$ inhibits NK activity in healthy pregnant women, whereas 100 -fold higher concentrations are 


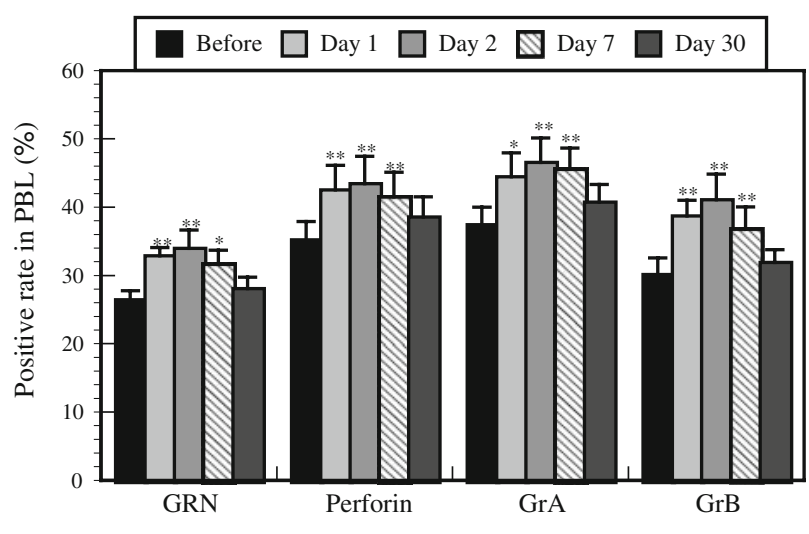

Fig. 7 Effect of a forest bathing trip on the levels of GRN-, perforin-, and GrA/B-expressing cells in PBLs. Data are presented as the mean $\pm \mathrm{SE}(n=13) .{ }^{*} P<0.05,{ }^{*} * P<0.01$, significantly different from before the trip by paired $t$ test. Cited from Li et al. [4]

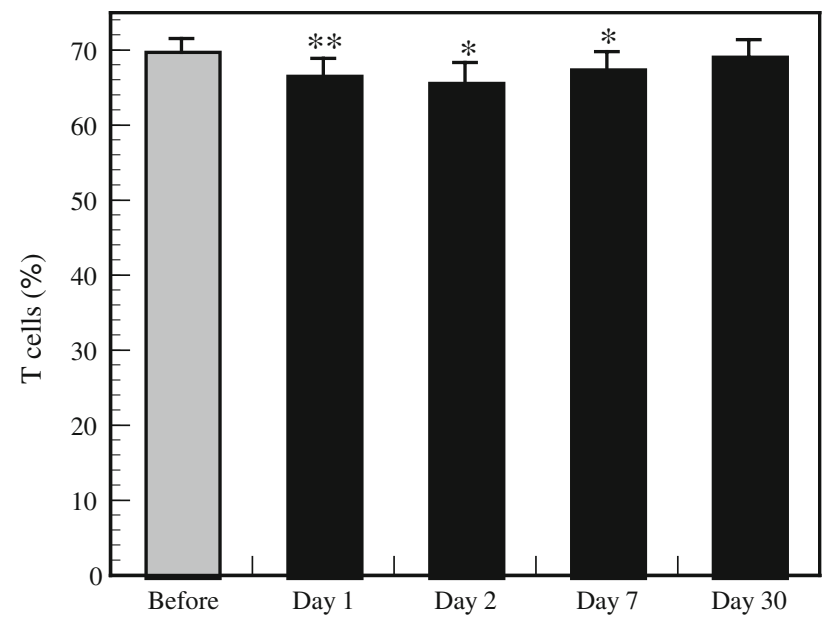

Fig. 8 Effect of the forest bathing trip on the percentage of T cells. Data are presented as the mean $\pm \operatorname{SE}(n=13) . * P<0.05$, $* * P<0.01$, significantly different from before the trip by paired $t$ test. Cited from Li et al. [4]

required for reducing NK activity in non-pregnant women [22]. These suggest that the menstrual cycle and the levels of estradiol and progesterone in serum may affect human NK activity.

To control for the influence of menstrual cycle on NK activity, a questionnaire was administered to obtain information on the menstrual cycle of the subjects. The ratios of subjects who were in the follicular phase during the experiment were $5 / 13,6 / 13,6 / 13,7 / 13$, and $6 / 13$ on the day before the trip, days 1 and 2 during the trip, and days 7 and 30 after the trip, respectively, indicating that there was no significant difference in the proportion of women in different phases of the menstrual cycle between the different days. This observation suggests that the menstrual cycle had a similar influence on the average of NK activity on the different days. Therefore, statistical analyses to compare the mean values of NK activity on the different days by a paired $t$ test should be appropriate. In addition, the concentrations of estradiol and progesterone in the serum of the subjects were also measured to confirm the influence of estradiol and progesterone on NK activity. In this study, there was no significant difference in the concentration of estradiol in serum between the days before, during, and after the forest bathing trip, indicating that, in this case, estradiol had a similar effect in all subjects on NK activity on the different days. Although the levels of progesterone on days 1 and 2 were higher than that before the study, the difference in serum progesterone concentration between days 1 or 2 and before the trip was not significant, suggesting that progesterone had a similar effect on NK activity on the different days [4].

Many factors, including circadian variation [23], physical exercise [16, 24], and alcohol consumption [16, 25], can affect human NK activity. In order to control for the effect of circadian rhythm on NK activity, blood was sampled at 0800 hours on all days [2-4]. To control for the effect of physical exercise on NK activity, the number of steps taken during the walking trips were limited to average normal workday distances, as monitored by a pedometer. The levels of physical activity among all trips were also matched. To control for the effect of alcohol on NK activity, the subjects did not consume alcohol for 2 days before providing the blood sample during the study period for both trips, including before the trips and after the trips on days 7 and 30. The number of hours spent sleeping during the trips were slightly more than those on average working days; however, the difference was not significant in either type of trip. Kusaka et al. [26] reported that the number of sleeping hours did not affect NK activity or NK cell numbers under physiological conditions. Li et al. [16] also found that there was no difference in the number of NK cells or the levels of perforin-, GRN-, or GrA/ B-expressing cells in PBL among subjects who slept for 5, 6 , or $7 \mathrm{~h}$, respectively. In addition, although the number of hours slept during the city tourist visit were slightly more than those on an average working days, the NK activities during the trip were almost the same as for working days, indicating that the longer sleeping hours did not affect NK activity in the city tourist visit [3]. Taken together, it can be concluded that although the number of sleeping hours during the trips was slightly higher than those on average working days, this difference did not affect NK activity or cell numbers in the city tourist trip.

\section{Effect of forest bathing trips on stress hormones}

Adrenaline is released from the adrenal medulla, and adrenaline levels increase under circumstances of novelty, 

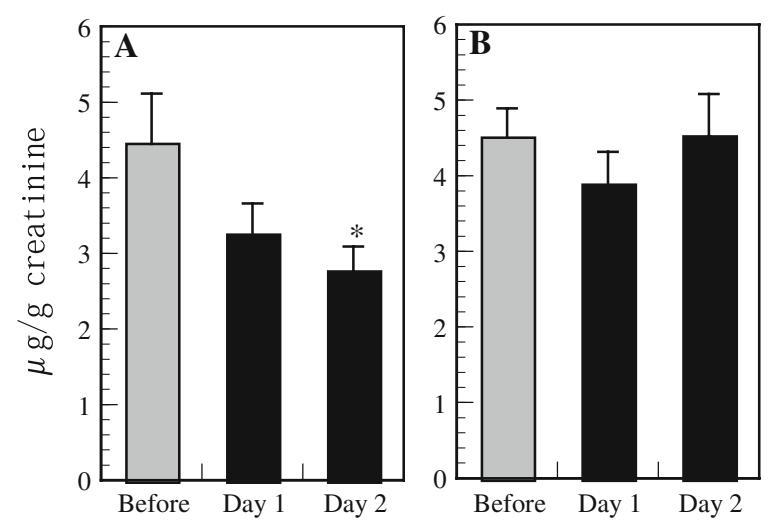

Fig. 9 Effect of a forest bathing trip on adrenaline and noradrenaline concentrations in urine. a Effect of a forest bathing trip on urinary adrenaline concentration in male subjects $(n=12)$, $\mathbf{b}$ effect of a city trip on urinary adrenaline concentration in male subjects $(n=11)$, c effect of a forest bathing trip on urinary adrenaline concentration in

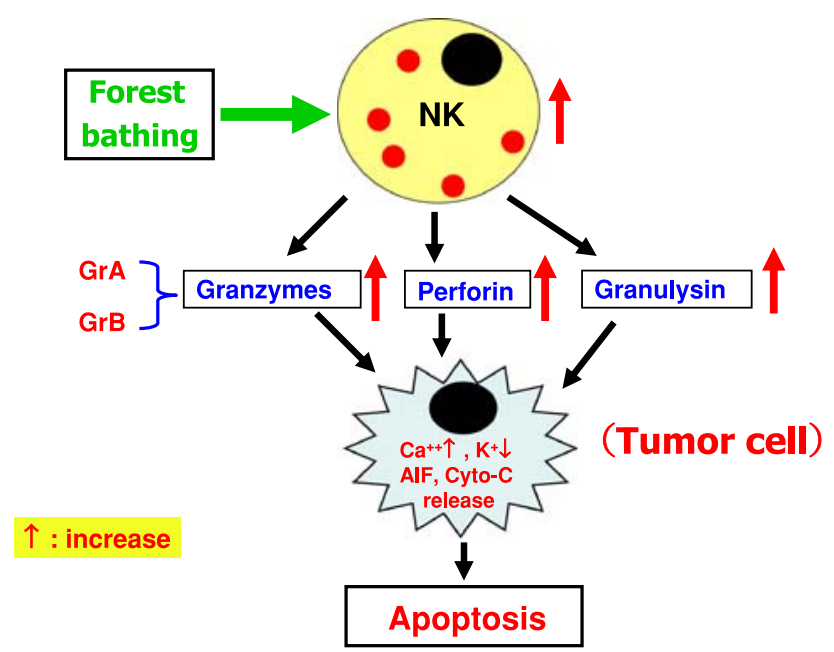

Fig. 10 Mechanism of forest bathing-induced induction in NK activity. AIF Apoptosis-inducing factor, Cyto-c cytochrome c

anticipation, unpredictability, and general emotional arousal. Noradrenaline is the predominant neurotransmitter released by the sympathetic system, and some of this enters the blood; the level of noradrenaline increases during increased physical activity [27]. The measurement of free adrenaline and noradrenaline in urine provides a reliable measure of the circulating concentration of adrenaline and noradrenaline in the bloodstream and, is, therefore, is a measure of sympathoadrenal medulla activity [28]. The concentrations of adrenaline and noradrenaline in urine have been used to evaluate work-related stress in nurses [29] and truck drivers [30], and the subjects were found to show decreases in adrenaline and/or noradrenaline in urine with lower stress. Forest bathing trips were found to significantly decrease urine adrenaline and noradrenaline concentrations in both male (Fig. 9a) [3] and female
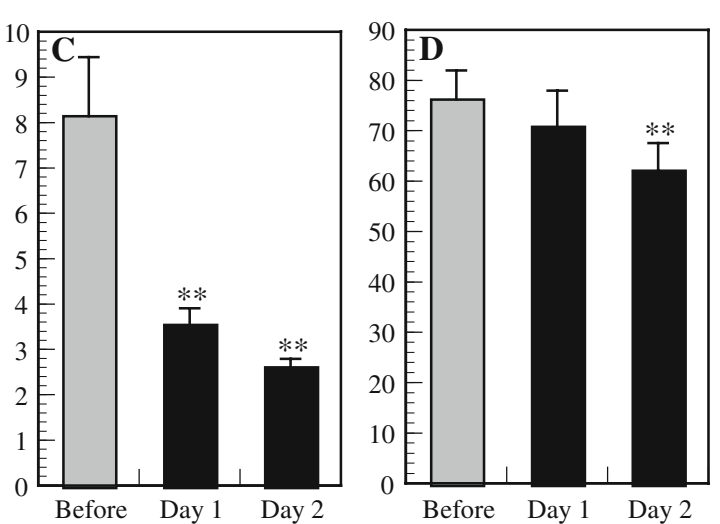

female subjects $(n=13)$, $\mathbf{d}$ effect of a forest bathing trip on urinary noradrenaline concentration in female subjects $(n=13)$. Data are presented as the mean \pm SE. $* P<0.05,{ }^{*} P<0.01$, significantly different from before the trip by paired $t$ test. Cited from Li et al. [3] and [4]

subjects (Fig. 9c, d) [4], while a city tourist visit had no effect (Fig. 9b) [3]. This result suggests that the subjects were under lower stress during the forest bathing trips [3, 4]. Garland et al. reported that adrenaline inhibits human NK activity [31]. The addition of noradrenaline to intrathecal morphine augments the postoperative suppression of NK cell activity [32], suggesting that noradrenaline also inhibits human NK activity. Li et al. [33] reported that physical and/or psychological stress decreases NK activity, NK receptor levels, and mRNA transcription levels of granzymes and perforin in mice. The increase in NK activity during forest bathing trips may be related to an attenuated stress hormone response (adrenaline, noradrenaline) associated with the forest bathing trip, whereas increased sympathetic activity may have an immunosuppressive effect through the release of adrenaline [34]. Other studies have reported that forest bathing trips reduce saliva cortisol levels, prefrontal cerebral activity, and blood pressure in humans, as well as stabilize autonomic nervous activity [35-37]. In addition, in studies using the POMS test, forest bathing trips were found to significantly increase the score for vigor and decrease the scores for anxiety, depression, and anger, suggesting that the subjects were physiologically relaxed during the forest bathing trips [2, 4]. One of these studies [2] also demonstrated that a forest bathing trip significantly increased the proportions of lymphocytes and monocytes and decreased the proportions of granulocytes in WBC [2]. It has been reported that dominance by the parasympathetic nervous system causes an increase in circulating lymphocytes and decrease in granulocytes in peripheral blood [38]. This mechanism suggests indirectly that the parasympathetic nervous system, which is associated with relaxation and decreased stress, was dominant in the subjects during the forest bathing trips. 


\section{Conclusions}

These findings indicate that forest bathing trips increase NK activity, which was mediated by increases in the number of NK cells and the levels of intracellular anticancer proteins (Fig. 10). Phytoncides released from trees and the decreased production of stress hormones may partially contribute to the increased NK activity.

Because NK cells can kill tumor cells by releasing anticancer proteins, such as perforin, GRN, and $\mathrm{GrA} / \mathrm{B}$, and forest bathing trips increase NK activity and the intracellular level of anti-cancer proteins, the above findings suggest that forest bathing trips may have a preventive effect on cancer generation and development.

Acknowledgments Parts of the experimental data shown in this review and performed by author were supported by a grant from the Ministry of Education, Culture, Sports, Science, and Technology of Japan (No. 16107007). This project is a collaboration with Professor Yoshifumi Miyazaki at Chiba University, Professor Kanehisa Morimoto at Osaka University, Mr. Takahide Kagawa, Forestry and Forest Products Research Institute, and Dr. Tomoyuki Kawada, Department of Hygiene and Public Health, Nippon Medical School (Professor and Chief). The author is grateful to the staff of Department of Hygiene and Public Health, Nippon Medical School for their technical assistance in the experiments.

\section{References}

1. Li Q, Nakadai A, Matsushima H, Miyazaki Y, Krensky AM, Kawada T, et al. Phytoncides (wood essential oils) induce human natural killer cell activity. Immunopharmacol Immunotoxicol. 2006;28:319-33.

2. Li Q, Morimoto K, Nakadai A, Inagaki H, Katsumata M, Shimizu $\mathrm{T}$, et al. Forest bathing enhances human natural killer activity and expression of anti-cancer proteins. Int $\mathrm{J}$ Immunopathol Pharmacol. 2007;20:3-8.

3. Li Q, Morimoto K, Kobayashi M, Inagaki H, Katsumata M, Hirata $Y$, et al. Visiting a forest, but not a city, increases human natural killer activity and expression of anti-cancer proteins. Int J Immunopathol Pharmacol. 2008;21:117-28.

4. Li Q, Morimoto K, Kobayashi M, Inagaki H, Katsumata M, Hirata Y, et al. A forest bathing trip increases human natural killer activity and expression of anti-cancer proteins in female subjects. J Biol Regul Homeost Agents. 2008;22:45-55.

5. Yamaguchi M, Deguchi M, Miyazaki Y. The effects of exercise in forest and urban environments on sympathetic nervous activity of normal young adults. J Int Med Res. 2006;34:152-9.

6. Morita E, Fukuda S, Nagano J, Hamajima N, Yamamoto H, Iwai Y, et al. Psychological effects of forest environments on healthy adults: Shinrin-yoku (forest-air bathing, walking) as a possible method of stress reduction. Public Health. 2007;121:54-63.

7. Forestry Agency of Japan. Available at: http://www.rinya.maff.go. jp/toukei/genkyou/shinrin-jinkou.htm. (2002).

8. Li Q, Nakadai A, Ishizaki M, Morimoto K, Ueda A, Krensky AM, et al. Dimethyl 2, 2-dichlorovinyl phosphate (DDVP) markedly decreases the expression of perforin, granzyme A and granulysin in human NK-92CI cell line. Toxicology. 2005;213:107-16.

9. Li Q, Kobayashi M, Kawada T. DDVP markedly decreases the expression of granzyme B and granzyme $3 / \mathrm{K}$ in human NK cells. Toxicology. 2008;243:294-302.
10. Li Q, Nagahara N, Takahashi H, Takeda K, Okumura K, Minami M. Organophosphorus pesticides markedly inhibit the activities of natural killer, cytotoxic T lymphocyte and lymphokine-activated killer: a proposed inhibiting mechanism via granzyme inhibition. Toxicology. 2002;172:181-90.

11. Li Q, Nakadai A, Takeda K, Kawada T. Dimethyl 2, 2-dichlorovinyl phosphate (DDVP) markedly inhibits activities of natural killer cells, cytotoxic $\mathrm{T}$ lymphocytes and lymphokine-activated killer cells via the Fas-ligand/Fas pathway in perforin-knockout (PKO) mice. Toxicology. 2004;204:41-50.

12. Okada S, Li Q, Whitin JC, Clayberger C, Krensky AM. Intracellular mediators of granulysin-induced cell death. J Immunol. 2003;171:2556-62.

13. Komori T, Fujiwara R, Tanida M, Nomura J, Yokoyama MM. Effects of citrus fragrance on immune function and depressive states. Neuroimmunomodulation. 1995;2:174-80.

14. da Silva SL, Figueiredo PM, Yano T. Chemotherapeutic potential of the volatile oils from Zanthoxylum rhoifolium Lam leaves. Eur J Pharmacol. 2007;576:180-8.

15. Grassmann J, Hippeli S, Vollmann R, Elstner EF. Antioxidative properties of the essential oil from Pinus mugo. J Agric Food Chem. 2003;51:7576-82.

16. Li Q, Morimoto K, Nakadai A, Qu T, Matsushima H, Katsumata $\mathrm{M}$, et al. Healthy lifestyles are associated with higher levels of perforin, granulysin and granzymes A/B-expressing cells in peripheral blood lymphocytes. Prev Med. 2007;44:117-23.

17. Bargellini A, Barbieri A, Rovesti S, Vivoli R, Roncaglia R, Borella P. Relation between immune variables and burnout in a sample of physicians. Occup Environ Med. 2000;57:453-7.

18. Glover DA, Steele AC, Stuber ML, Fahey JL. Preliminary evidence for lymphocyte distribution differences at rest and after acute psychological stress in PTSD-symptomatic women. Brain Behav Immun. 2005;19:243-51.

19. Souza SS, Castro FA, Mendonça HC, Palma PV, Morais FR, Ferriani RA, et al. Influence of menstrual cycle on NK activity. J Reprod Immunol. 2001;50:151-9.

20. Yovel G, Shakhar K, Ben-Eliyahu S. The effects of sex, menstrual cycle, and oral contraceptives on the number and activity of natural killer cells. Gynecol Oncol. 2001;81:254-62.

21. Roszkowski PI, Hyc A, Stopińska-Głuszak U, Malejczyk J. Natural killer cell activity and sex hormone levels in mastopathy. Gynecol Endocrinol. 1997;11:399-404.

22. Szekeres-Bartho J, Polgar B, Kozma N, Miko E, Par G, Szereday $\mathrm{L}$, et al. Progesterone-dependent immunomodulation. Chem Immunol Allergy. 2005;89:118-25.

23. Angeli A. Circadian rhythms of human NK cell activity. Chronobiologia. 1992;19:195-8.

24. Nieman DC. Special feature for the Olympics: effects of exercise on the immune system: exercise effects on systemic immunity. Immunol Cell Biol. 2000;78:496-501.

25. Ochshorn-Adelson M, Bodner G, Toraker P, Albeck H, Ho A, Kreek MJ. Effects of ethanol on human natural killer cell activity: in vitro and acute, low-dose in vivo studies. Alcohol Clin Exp Res. 1994;18:1361-7.

26. Kusaka Y, Kondou H, Morimoro K. Healthy lifestyles are associated with higher natural killer cell activity. Prev Med. 1992;21:602-15.

27. Frankenhaeuser M. Experimental approach to the study of catecholamines and emotion. In: Levi L, editor. Emotions, their parameters and measurement. New York: Raven Press; 1975. 209pp.

28. Moleman $\mathrm{P}$, Tulen $\mathrm{JH}$, Blankestijn PJ, Man in 't Veld AJ, Boomsma F. Urinary excretion of catecholamines and their metabolites in relation to circulating catecholamines. Six-hour infusion of epinephrine and norepinephrine in healthy volunteers. Arch Gen Psychiatry. 1992;49:568-72. 
29. Brown DE, James GD, Mills PS. Occupational differences in job strain and physiological stress: female nurses and school teachers in Hawaii. Psychosom Med. 2006;68:524-30.

30. van der Beek AJ, Meijman TF, Frings-Dresen MH, Kuiper JI, Kuiper S. Lorry drivers' work stress evaluated by catecholamines excreted in urine. Occup Environ Med. 1995;52:464-9.

31. Garland M, Doherty D, Golden-Mason L, Fitzpatrick P, Walsh N, O'Farrelly C. Stress-related hormonal suppression of natural killer activity does not show menstrual cycle variations: implications for timing of surgery for breast cancer. Anticancer Res. 2003;23:2531-5.

32. Yokota T, Uehara K, Nomoto Y. Addition of noradrenaline to intrathecal morphine augments the postoperative suppression of natural killer cell activity. J Anesth. 2004;18:190-5.

33. Li Q, Liang Z, Nakadai A, Kawada T. Effect of electric foot shock and psychological stress on activities of murine splenic natural killer and lymphokine-activated killer cells, cytotoxic $\mathrm{T}$ lymphocytes, natural killer receptors and mRNA transcripts for granzymes and perforin. Stress. 2005;8:107-16.
34. McClelland DC, Floor E, Davidson RJ, Saron C. Stressed power motivation, sympathetic activation, immune function, and illness. J Human Stress. 1980;6:11-9.

35. Park BJ, Tsunetsugu Y, Kasetani T, Hirano H, Kagawa T, Sato M, et al. Physiological effects of Shinrin-yoku (taking in the atmosphere of the forest)-using salivary cortisol and cerebral activity as indicators. J Physiol Anthropol. 2007;26:123-8.

36. Park BJ, Tsunetsugu Y, Ishii H, Furuhashi S, Hirano H, Kagawa T, et al. Physiological effects of Shinrin-yoku (taking in the atmosphere of the forest) in a mixed forest in Shinano Town, Japan. Scand J For Res. 2008;23:278-83.

37. Tsunetsugu Y, Park BJ, Ishii H, Hirano H, Kagawa T, Miyazaki Y. Physiological effects of Shinrin-yoku (taking in the atmosphere of the forest) in an old-growth broadleaf forest in Yamagata Prefecture, Japan. J Physiol Anthropol. 2007;26:13542.

38. Mori H, Nishijo K, Kawamura H, Abo T. Unique immunomodulation by electro-acupuncture in humans possibly via stimulation of the autonomic nervous system. Neurosci Lett. 2002;320:21-4. 